\title{
Reduction in cardiovascular emergency admissions in Monaco during the COVID-19 pandemic
}

\author{
Bogdan Enache ${ }^{1,5} \cdot$ Yann-Erick Claessens ${ }^{2} \cdot$ Fabrice Boulay $^{3} \cdot$ Vincent Dor $^{4} \cdot$ Armand Eker $^{4} \cdot$ Filippo Civaia $^{4}$. \\ Atul Pathak ${ }^{1}$
}

Received: 6 May 2020 / Accepted: 5 June 2020 / Published online: 12 June 2020

(c) Springer-Verlag GmbH Germany, part of Springer Nature 2020

Sirs:

As the COVID-19 pandemic is advancing around the world, more data are available about: the number of confirmed cases [1] and the estimates of mortality [2]. Surprisingly the rate of acute coronary syndromes (ACS) is decreased [3] and the rate of $\mathrm{CV}$ admission for other reasons could also have been reduced. Due to the geographic variability within countries it is difficult to assess if these results are driven by the SARS-CoV-2 infection, delays for admission [4] or fear of being hospitalized. The latter being a direct consequence of how patient perceive a stressful situation which should normally lead to an increase in the rate of $\mathrm{CV}$ admission as seen after terror attacks [5], earthquakes or even during football world cup.

In this report, we used the opportunity of the small size of the principality of Monaco (MC) combined with its wellorganized public health care system, to collect exhaustive data to explore the impact of COVID-19 on CV admission. MC situation allows for an unbiased and complete view of the dynamics of the country's cardiological admissions.

In the setting of COVID-19 pandemic, MC situation is of particular interest: it is one of the most densely populated countries in the world $\left(19,000\right.$ inhabitants $\left./ \mathrm{km}^{2}\right)$, enclaved between France and Italy, two of the countries with the

Bogdan Enache

bogdan.enache@chpg.mc

1 Department of Cardiovascular Medicine, Princess Grace Hospital, Monaco, Monaco

2 Emergency Department, Princess Grace Hospital, Monaco, Monaco

3 Department of Medical Information, Princess Grace Hospital, Monaco, Monaco

4 Cardiothoracic Center, Monaco, Monaco

5 University of Medicine and Pharmacy "Victor Babes", Timisoara, Romania biggest number of both overall COVID-19 cases (respectively 2325 and 2910 cases of per million) and fatalities. Hence, the prevalence of 2395 cases per million in MC is within these ranges.

We retrospectively analyzed the activity data of all cardiology departments within MC, but also all Emergencies departments in the first 3 months of 2020 and the first 3 months of 2019 dividing the data by whether they were scheduled admissions or emergency admissions. Given that the first COVID-19 case was reported on February 28th, splitting the data by month coincides with a natural before and after the start of the epidemic in MC. All admissions were checked for having a cardiological diagnostic or symptom using the CIM 10 medical classification system.

In March 2020, there were 346 cardiovascular admissions and 130 emergency admission in Monaco. Compared to February 2020, the total cardiovascular admissions were lower by $18 \%$, while compared to March 2019, they were lower by $17 \%$. Similarly, compared to February 2020 the emergency admissions were down by $23 \%$ and compared to March 2019, they were down by $21 \%$ (Fig. 1).

In this nationwide exhaustive report, we found a statistically significant reduction in hospitalization for both $\mathrm{CV}$ emergencies and total admissions. The reduction in emergency admissions is unexpected during or after viral infection [6]. It is in accordance with publications of colleagues showing that the rate of admission for ACS is reduced in neighboring France and Italy [4] but does not explain the reduction in hospitalization for heart failure, syncope or arrhythmia.

We and others have shown that during period of stress rate of hospitalization for $\mathrm{CV}$ cause is always increased, this epidemic situation is showing the opposite for the first time. This could be explained by: a strict adherence of patient to staying at home orders, the fear of getting infected with COVID once hospitalized, difficulties in reaching physicians or ED doctors for their symptoms, delay in transfer 
Fig. 1 Nationwide cardiovascular admissions in Monaco

\section{Nationwide Cardiovascular Admissions in Monaco}

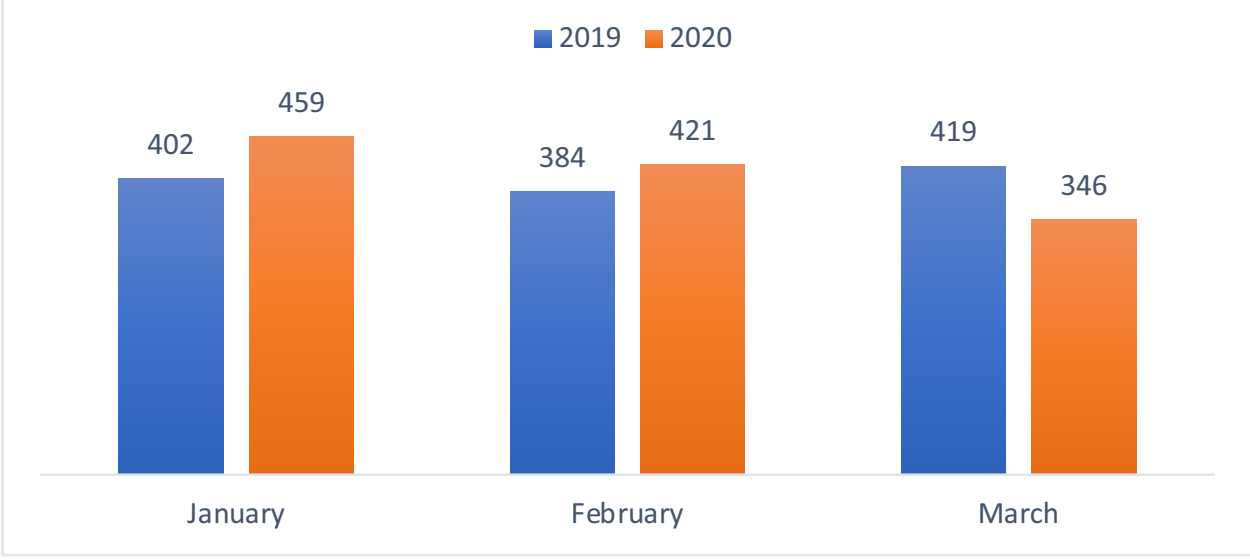

time from home to hospital due to an increased demand for COVID infected patient (Fig. 1).

For countries where lockdown is maintained our findings constitute a plea to increase awareness of healthcare stakeholders and education of patients to call emergency services if cardiac symptoms occur. In countries where lockdown is eased or ending, physicians should anticipate an outburst of cases with late $\mathrm{CV}$ complication.

\section{References}

1. COVID-19 Virus Pandemic-Worldometer. https://www.world ometers.info/coronavirus/\#countries. Accessed 4 May 2020

2. Baud D, Qi X, Nielsen-Saines K, Musso D, Pomar L, Favre G (2020) Real estimates of mortality following COVID-19 infection. Lancet Infect Dis. https://doi.org/10.1016/S1473-3099(20)30195-X
3. De Filippo O, D’Ascenzo F, Angelini F, Bocchino PP, Conrotto F, Saglietto A et al (2020) Reduced rate of hospital admissions for ACS during Covid-19 outbreak in Northern Italy. N Engl J Med. https:// doi.org/10.1056/NEJMc2009166

4. Rangé G, Hakim R, Motreff P (2020) Where have the STEMIs gone during COVID-19 lockdown? Eur Heart J Qual Care Clin Outcomes. https://doi.org/10.1093/ehjqcco/qcaa034

5. Rosa FD, Van Rothem J, Dongay B, Pathak A (2016) We are CHARLIE: emotional stress from "Charlie Hebdo attack" extensively relayed by media increases the risk of cardiac events. Clin Res Cardiol 105(7):630-631

6. Kwong JC, Schwartz KL, Campitelli MA, Chung H, Crowcroft NS, Karnauchow T et al (2018) Acute myocardial infarction after laboratory-confirmed influenza infection. N Engl J Med 378:345-353. https://doi.org/10.1056/NEJMoa1702090 